\section{Discussion}

The findings on the change in performance as a function of exposure disagree with Sperling's. ${ }^{2}$ The performance shows continuous changes as exposure duration increases. The findings indicate an upper limit of four to five letters reported from arrays of letters. These findings agree with Sperling's. The results for the binary numbers, which fall well above the range of four to five units, do not really contradict the latter findings. It is known that binary numbers permit grouping or encoding (Glanzer \& Clark, 1963) and that they therefore follow somewhat more complicated laws.

If the presentation procedure used is particularly favorable or if it tends to promote afterimages, maximal or asymptotic performance could be approached over a considerable range of exposure times. This may be the condition that was obtained in the Sperling and the Schumann experiments. Even near asymptote, however, sufficient measurement gives evidence of changes with increased exposure (see A). However, even though apparent invariance may be found under some experimental conditions, it certainly is not general. The general case is one in which there is a continuous change of performance when exposure time is varied.

\section{References}

Glanzer, M., \& Clark, W. H. The verbal loop hypothesis: binary numbers. J. verbal Learn. verbal Behav., 1963, 2, 301-309.

Karlin, L. The New York University Tachistoscope. Amer. J. Psychol., 1955, 462-466.

Schumann, F. Die Erkennung von Buchstaben und Worten bei momentaner Beleuchtigung. In: Beticht uber den erste Kongress fur experimentelle Psychologie. Leipzig: Barth, 1904. Pp. 34-40.

Sperling, $G$. The information available in brief visual presentation. Psychol. Monogr., 1960, 74, No. 11 (Whole No. 498).

Sperling, G. A model for visual memory tasks. Hum. Factors, 1963 , $5,19-31$.

Sperling, G. Successive approximations to a model for short-term memory. Proc. 18th Int. Congr. Psychol., Moscow, 1966, Amsterdam: North Holland Publishing Co., in press.

\section{Nofes}

1. This study was carried out under Research Contract DA-49-193MD-2496, U. S. Army Medical Research and Development Command, Department of the Army. We thank Julian E. Hochberg for his critical reading of an earlier draft of the paper.

2. Since preparation of this paper, Sperling (in press) has presented data that show continuity of the effect of exposure duration on the perception of letters ( 10 to $200 \mathrm{msec}$.).

\title{
The A test: A simplification of the t test for correlated samples by Robert Zenhausern
}

A statistically identical version of the correlated "t" test was compared with the latter. Method of calculation, determination of significance, and advantages were discussed.

A frequently used experimental design involves testing the same Ss under two conditions. Statistically, this is usually handled through the use of a correlated $t$ test, based on the differences between the two scores for each individual. A typical formula, found in Ferguson (1966), is as follows:

$$
t=\frac{\sum D}{\sqrt{N \Sigma D^{2}-(\Sigma D)^{2} / N-1}}
$$

where $D$ refers to the signed differences between the two conditions for one S.

A statistically identical, although much simpler, formula has been developed by Sandler (1955). The modification, designated the A test, is calculated as follows:

$$
A=\frac{\Sigma D^{2}}{(\Sigma D)^{2}}
$$

where $D$ has the same meaning as in the $t$ test.

An examination of the formula makes it evident that the smaller the A value, the more significant the difference, since $\Sigma D$ increases as the scores for one condition are consistently greater or smaller than the scores from the other condition. The A values needed for significance can be determined from the $t$ value needed for significance through the use of the following conversion:

$$
t=\sqrt{\frac{N-1}{A N-1}}
$$

where $\mathbf{N}$ is the number of Ss and $t$ is the value needed for significance. Tables of A appear in Sandler's (1955) article and McGuigan's (1960) book.

There are two main advantages to the "A" test: (1) The calculations are simple. (2) The A test is actually more accurate than the correlated $t$ test, since rounding errors are non-existent in the $\mathrm{A}$ test.

The only disadvantage of the "A" test is the relative scarcity of tables of A. A one-time calculation of these values, however, will solve this problem. Furthermore, as the test becomes better known, tables of $A$ will be more available. For some reason, this test is virtually unknown among psychologists, and seems to have been mentioned only by McGuigan (1960). The A test is a simple, more accurate version of the correlated $t$ test. It should be taught in all elementary statistics courses and ultimately replace the relatively cumbersome "t."

\section{References}

Ferguson, S. A. Statistical analysis in psychology and education. New York: McGraw-Hill, 1966.

McGuigan, F. J. Experimental psychology. Englewood Cliffs: Prentice-Hall, 1960.

Sandler, J. A test of significance of the difference between the means of correlated measures, based on a simplification of student's "t"'. Brit. J. Psychol., 1955, 46, 225-226. 